\title{
OTIMIZAÇÃO DA EFICIÊNCIA NUTRICIONAL NA PRODUÇÃO DAS CULTURAS
}

\author{
Nand Kumar Fageria ${ }^{1}$
}

\begin{abstract}
RESUMO
O fornecimento adequado de nutrientes contribui, de forma significativa, tanto no aumento da produtividade como no aumento do custo da produção. Nesta situação, a otimização de eficiência nutricional é fundamental para ampliar a produtividade e reduzir o custo de produção. Vários fatores, como clima, solo, planta e suas interações, afetam a absorção e a utilização de nutrientes pelas plantas. Para a eficiência máxima de nutrientes, esses fatores devem estar no nível ótimo durante o desenvolvimento da cultura e a revisão de literatura mostra que existe grande potencial de se aumentar a eficiência nutricional através do manejo adequado dos componentes do sistema de produção.
\end{abstract}

Palavras-chave: culturas anuais, absorção e utilização de nutrientes, comprimento das raízes, variabilidade genética

\section{OPTIMIZING NUTRIENT USE EFFICIENCY IN CROP PRODUCTION}

\begin{abstract}
The adequate supply of nutrients contributes significantly to increasing crop produtivity as well as cost of production. In this situation, optimizing nutrient use efficiency is fundamental for higher crop productivity and reduced cost of production. Several factors such as climate, soil, plant, and their interactions affect nutrient absorption and utilization by crop plants. To obtain maximum nutrient use efficiency, all these factors should be at an optimum level during crop development. A review of factors affecting nutrient use efficiency demonstrates a large potential to improve nutrient use efficiency by adequate management of cropping system components.
\end{abstract}

Key words: annual crops, nutrient absorption and utilization, root length, genetic variability

\section{INTRODUÇÃO}

A otimização da eficiência nutricional é de grande importância na produção das culturas anuais, devido ao custo dos fertilizantes, imprescindíveis para o aumento da produtividade (Fageria, 1984a, 1989, 1992; Lopes \& Guilherme, 1989). Na agricultura moderna, esse custo contribui, em média, com aproximadamente $30 \%$ do custo total de produção. O aumento da produtividade com a adubação depende das características químicas e físicas do solo e da cultura plantada, de outros fatores, como disponibilidade de água, controle de doenças, pragas e invasoras e do uso de cultivares. Os principais fatores que limitam a produtividade das culturas em solos aráveis em várias partes do mundo estão apresentados na Tabela 1, dentre os quais se destacam, como limitantes, a deficiência hídrica e o estresse nutricional. Um exemplo neste sentido são os solos do Cerrado Brasileiro que, em condições naturais, são pobres em nutrientes essenciais às plantas, principalmente em fósforo. A resposta de

\footnotetext{
${ }^{1}$ Eng. Agr., Ph.D., Embrapa Arroz e Feijão, Bolsista do CNPq. CP 179, CEP 74001-970 Goiânia, GO. Fone: (062) 833-2178, Fax: (062) 833-2100, E-mail: fageria@cnpaf.embrapa.br
} 
várias culturas anuais à aplicação de fósforo em solo de Cerrado pode ser observada na Figura 1; houve aumento significativo na produtividade com a aplicação de fósforo, mas a magnitude da resposta variou de cultura para cultura.

A eficiência de recuperação de nutrientes pelas culturas anuais é muito baixa; por exemplo, em média a eficiência de $\mathrm{N}$ é de $50 \%$, de $\mathrm{P}$ de $10 \%$ e de $\mathrm{K}$ de $40 \%$ (Baligar \& Bennett, 1986).

produzida por unidade de nutriente aplicado; entretanto, na literatura a eficiência nutricional é definida de várias maneiras. De acordo com Graham (1984) esta eficiência pode ser definida como a produção relativa de um genótipo em solo deficiente em comparação com sua produção no nível ótimo de nutrientes. Cooke (1987) define a eficiência nutricional como o aumento de produtividade por unidade de nutriente aplicado. De acordo

Tabela 1. Principais limitações na produção agrícola em várias regiões do mundo

\begin{tabular}{lcccccc}
\hline \multirow{2}{*}{ Regiões } & \multicolumn{5}{c}{ Porcentagem de área total } \\
\cline { 2 - 7 } & $\begin{array}{c}\text { Deficiência } \\
\text { hídrica }\end{array}$ & $\begin{array}{c}\text { Estresse } \\
\text { nutricional }\end{array}$ & $\begin{array}{c}\text { Baixa profundidade } \\
\text { do solo }\end{array}$ & $\begin{array}{c}\text { Excesso de } \\
\text { água }\end{array}$ & $\begin{array}{c}\text { Geleira } \\
\text { permanente }\end{array}$ & $\begin{array}{c}\text { Sem maior } \\
\text { limitação }\end{array}$ \\
\hline América do Norte & 20 & 22 & 10 & 10 & 16 & 22 \\
América Central & 32 & 16 & 17 & 10 & - & 25 \\
América do Sul & 17 & 47 & 11 & 10 & - & 15 \\
Europa & 8 & 33 & 12 & 8 & 3 & 36 \\
Africa & 44 & 18 & 13 & 9 & 3 & 16 \\
Asia Sul & 43 & 5 & 23 & 11 & - & 18 \\
Asia Norte e Central & 17 & 9 & 38 & 13 & 13 & 10 \\
Asia Sudeste & 2 & 59 & 6 & 19 & - & 14 \\
Australia & 55 & 6 & 8 & 16 & - & 15 \\
Mundo & 28 & 23 & 22 & 10 & 6 & 11 \\
\hline
\end{tabular}

Fonte: Dent (1980)

Um trabalho realizado por Coelho et al. (1991) em solo de Cerrado, com milho, mostrou que de $60 \mathrm{~kg}$ de N/ha aplicados na forma de uréia, $56 \%$ foram extraídos pela cultura. A baixa eficiência nutricional está relacionada com condições adversas de clima, solo e planta. Para se aumentar a eficiência nutricional é necessário se entender melhor o efeito desses fatores na absorção e na utilização de nutrientes pela planta; portanto, o objetivo deste trabalho é discutir os fatores que influenciam a disponibilidade de nutrientes para a planta e sugerir práticas de manejo para aumentar a eficiência nutricional.

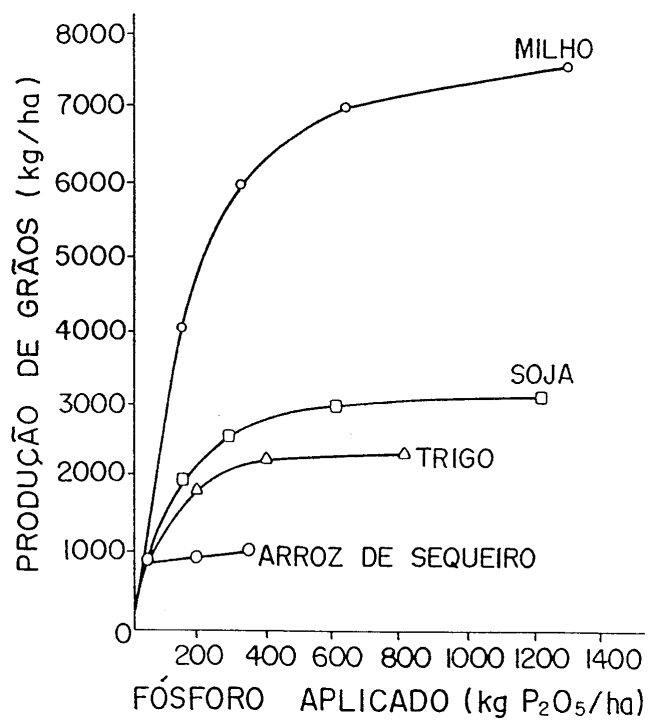

Figura. 1. Resposta das culturas a aplicação de fósforo a lanço em solo de cerrado (adaptado de Lobato, 1982)

\section{DEFINIÇÕESDE EFICIÊNCIANUTRICIONAL}

Em geral, a eficiência pode expressar a relação entre produção obtida e insumos aplicados; isto significa que a eficiência nutricional é a quantidade de matéria seca ou grãos
Eficiência agronômica

Produção em kg com adubação Quantidade de nutriente aplicado em kg

Às vezes, a eficiência agronômica é também chamada eficiência econômica. Em experimento de campo, a eficiência agronômica é geralmente expressa em $\mathrm{kg}$ do produto $/ \mathrm{kg}$ de nutriente $\left(\mathrm{kg}^{\mathrm{kg}} \mathrm{kg}^{-1}\right)$. A eficiência agronômica de $\mathrm{N}$ de algumas cultivares de arroz de sequeiro em Latossolo do Brasil Central é apresentada na Tabela 2 e, se a eficiência é determinada em experimentos em condições controladas, pode ser expressa em $\mathrm{gg}^{-1}$ ou $\mathrm{mgmg}^{-1}$.

Tabela 2. Eficiência agronômica de cultivares de arroz de sequeiro em solo de cerrado

\begin{tabular}{lccc}
\hline \multirow{2}{*}{$\begin{array}{l}\text { Lultivar/ } \\
\text { Linhagem }\end{array}$} & \multicolumn{3}{c}{ Produção de grãos (kg/ha) } \\
\cline { 2 - 4 } & \multicolumn{3}{c}{$\begin{array}{l}\text { Eficiência de N } \\
(\mathrm{kg} \text { grãos/kg N) }\end{array}$} \\
\hline IAC 114 & 2319 & 2800 & 14 \\
CNA 790124 & 3208 & 4075 & 25 \\
CNA 800160 & 2929 & 3142 & 6 \\
IAC 136 & 2198 & 2278 & 2 \\
IAC 165 & 1232 & 1578 & 10 \\
IR 20 & 1040 & 1330 & 8 \\
CN 770538 & 896 & 1687 & 23 \\
IR 144 & 1405 & 1483 & 2 \\
IRAT 134 & 959 & 1073 & 3 \\
\hline
\end{tabular}

Fonte: Fageria et al. (1997)

Eficiência fisiológica: é a produção biológica obtida (grãos + palha, em culturas anuais) por unidade de nutriente acumulado. Às vezes, esta eficiência é também chamada eficiência biológica e pode ser calculada pela seguinte equação:

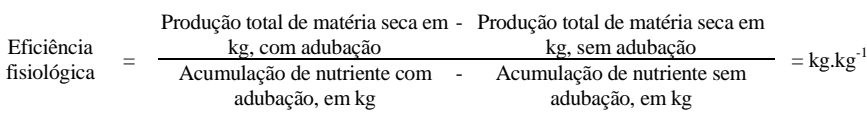


A acumulação de nutrientes é calculada por meio da multiplicação do peso da matéria seca da parte aérea e de grãos pelo teor do nutriente.

Eficiência na produção de grãos: é a produção de grão obtida por unidade de nutriente acumulado e pode ser calculada pela seguinte equação:

$$
\begin{aligned}
& \begin{array}{c}
\text { Eficiência na produção } \\
\text { de grãos }
\end{array}=\frac{\begin{array}{c}
\text { Produção de grãos em kg, com } \\
\text { adubação }
\end{array}}{\begin{array}{c}
\text { Acumulação de nutriente na parte }-\begin{array}{c}
\text { Acumulação de nutriente na parte } \\
\text { aérea e grãos em kg, com }
\end{array} \\
\text { aérea e grãos em } \mathrm{kg} \text {, sem }
\end{array}}=\mathrm{kg} \cdot \mathrm{kg}^{-1} \\
& \text { adubação adubação }
\end{aligned}
$$

A eficiência de N, P e K na produção de grãos pelos genótipos de arroz de sequeiro em solo de cerrado é apresentada na Tabela 3.

Tabela 3. Eficiência de utilização de N, P e K pelos genótipos de arroz de sequeiro no solo de cerrado

\begin{tabular}{lccr}
\hline \multirow{2}{*}{ Genótipos } & \multicolumn{3}{c}{ kg de grãos/kg nutriente acumulado } \\
\cline { 2 - 4 } & $\mathrm{N}$ & $\mathrm{P}$ & $\mathrm{K}$ \\
\hline CNA 7013-D & 62 & 376 & 52 \\
Araguaia & 24 & 413 & 16 \\
IAC 84-198 & 51 & 503 & 99 \\
IAC 1175 & 47 & 458 & 33 \\
CNA 6710 & 34 & 376 & 48 \\
CNA 7024 & 37 & 858 & 38 \\
CNA 7066 & 25 & 395 & 303 \\
IAC 1176 & 41 & 288 & 46 \\
Média & 40 & 458 & 79 \\
\hline
\end{tabular}

Fonte: Fageria et al. (1994)

Eficiência de recuperação: é a quantidade de nutriente acumulado por unidade de nutriente aplicado; a eficiência de recuperação de nutriente pode ser calculada pela seguinte equação:

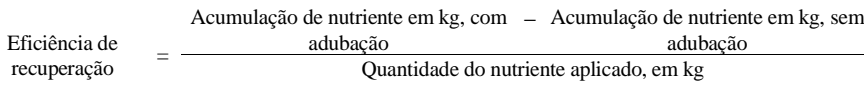

A eficiência de recuperação de nutriente é geralmente expressa em porcentagem; às vezes, a eficiência de recuperação é também chamada eficiência de aquisição de nutriente.

Eficiência de utilização: a eficiência fisiológica e a eficiência de recuperação podem ser combinadas para se calcular a eficiência da utilização de nutriente, como expressa a seguinte equação:

$\underset{\text { Eficiência de utilização de }}{\text { nutriente }}=$ Eficiência fisiológica $\quad \mathrm{x} \quad \begin{aligned} & \text { Eficiência de } \\ & \text { recuperação }\end{aligned}=\mathrm{kg} \cdot \mathrm{kg}^{-1}$

Na literatura (Bailian et al., 1991; Martinez et al., 1993a, 1993b) às vezes a eficiência nutricional é também chamada eficiência de absorção; além dela, são mencionadas, ainda, a eficiência de enraizamento e a de conversão de biomassa. A eficiência de absorção é a quantidade de nutriente absorvido por unidade de matéria seca das raízes. A de enraizamento é a produção de matéria seca das raízes por unidade de nutriente absorvida; já a eficiência de conversão em biomassa é a produção de matéria seca da parte aérea por unidade de nutriente na parte aérea.

Em solo com baixa fertilidade, a eficiência de utilização de nutriente é mais importante que a eficiência de absorção (Moll et al., 1982; Sanford \& Mackown, 1986); entretanto, Moll et al.
(1982) recomendam que, em desenvolvimento de genótipos para estresse nutricional, é importante levar-se em consideração a eficiência de absorção e a de utilização; ambas as características devem ser incorporadas para aumentar a eficiência nutricional.

Teoricamente, a eficiência nutricional diminui com níveis crescentes de um nutriente, se houve resposta da cultura, devido à diminuição relativa da produção com sucessiva adição de nutriente; entretanto, o produtor recebe maior lucro com a alta produtividade, significando que melhor eficiência nutricional é aquela obtida sob nível de nutriente adequado em que a produtividade máxima foi obtida; portanto, deve-se tomar cuidado na interpretação de resultados de eficiência nutricional.

\section{FATORES QUE AFETAM A EFICIÊNCIA NUTRICIONAL}

Os vários fatores que afetam a produtividade das culturas também afetam a eficiência nutricional. Estes fatores são ligados as condições ambientais como clima, solo e planta.

\section{Clima}

Fatores climáticos, como temperatura, radiação solar e precipitação, influenciam a produtividade das culturas e, conseqüentemente, a eficiência nutricional.

\section{Temperatura}

A temperatura é um dos fatores climáticos que mais afetam o crescimento da planta. Há temperaturas críticas, tanto baixas quanto altas, para cada uma das diferentes fases de crescimento das culturas; em média, as temperaturas críticas baixas são normalmente menores que $20^{\circ} \mathrm{C}$ e as temperaturas críticas altas são maiores que $30^{\circ} \mathrm{C}$ para as principais culturas anuais (Fageria, 1989). A temperatura do solo influencia a taxa de liberação de nutrientes da matéria orgânica, a absorção pelas raízes e a subseqüente translocação e utilização em várias partes da planta.

\section{Radiação solar}

O aspecto crítico de radiação solar como fator ambiental, está ligado à intensidade e à duração da luz. O processo de fotossíntese depende da radiação solar, a qual, por sua vez, oferece energia para conversão de $\mathrm{CO}_{2}$ e $\mathrm{H}_{2} \mathrm{O}$ em composto orgânico. A taxa de fotossíntese aumenta com o aumento de intensidade da luz até certo ponto e, depois, o processo é independente desta. A intensidade de luz favorável varia de cultura para cultura; a Tabela 4 mostra a necessidade de radiação solar para várias culturas. Comparando-se a importância relativa da radiação solar nos diferentes estádios de crescimento, em termos de produção de Tabela 4. Necessidade de radiação solar para algumas culturas anuais

\begin{tabular}{lrl}
\hline Cultura & $\begin{array}{c}\text { Necessidade de } \\
\text { radiação solar } \\
\text { (Klux) }\end{array}$ & \multicolumn{1}{c}{ Referência } \\
\hline Milho & $32-86$ & Wann (1977) \\
Algodão & $32-86$ & Edmond et al. (1975) \\
Amendoim & $22-86$ & Edmond et al. (1975) \\
Batata & $21,5-86$ & Edmond et al. (1975) \\
Arroz & $32-86$ & Edmond et al. (1975) \\
Cana-de-açúcar & 65 & Nickell (1977) \\
Batata-doce & $32-86$ & Edmond et al. (1975) \\
Trigo & 57 & Jen-Hu (1968) \\
\hline
\end{tabular}


grãos, vê-se o seu efeito marcante no estádio reprodutivo, seguido do estádio de maturação (Yoshida, 1981). Os efeitos gerais da radiação solar durante o estádio vegetativo, na produção, são extremamente pequenos (Yoshida, 1972).

\section{Precipitação}

Entre os fatores biofísicos, a água é o principal fator que determina a produção das culturas anuais e, conseqüentemente, a eficiência nutricional. A deficiência hídrica causa redução de vários processos fisiológicos e bioquímicos na planta, como fotossíntese, enlargamento das células e fixação biológica de $\mathrm{N}_{2}$ (Hsaio, 1973). A umidade do solo está significativamente correlacionada com todas as propriedades biológicas do solo (Wardle \& Parkinson, 1990). A deficiência hídrica reduz a produção, mas esta redução depende, sobretudo, do estádio de crescimento em que ocorre, da severidade e da duração da deficiência. A maioria das culturas anuais é mais sensível à deficiência hídrica do estádio de uma semana antes até a floração (Yoshida, 1972; Fageria, 1980; Grant et al., 1989; Nesmith \& Ritchie, 1992). A deficiência durante esta fase, no caso de arroz de sequeiro, aumenta a esterilidade, diminui o peso dos grãos e a produção (Fageria, 1980). Há interação entre umidade do solo e resposta das culturas à adubação (Campbell et al., 1993). A Figura 2 mostra a relação entre produção de grãos de milho e níveis de nitrogênio sob deficiência hídrica, durante o enchimento de grãos. A produção foi por demais reduzida com 14 a 34 dias

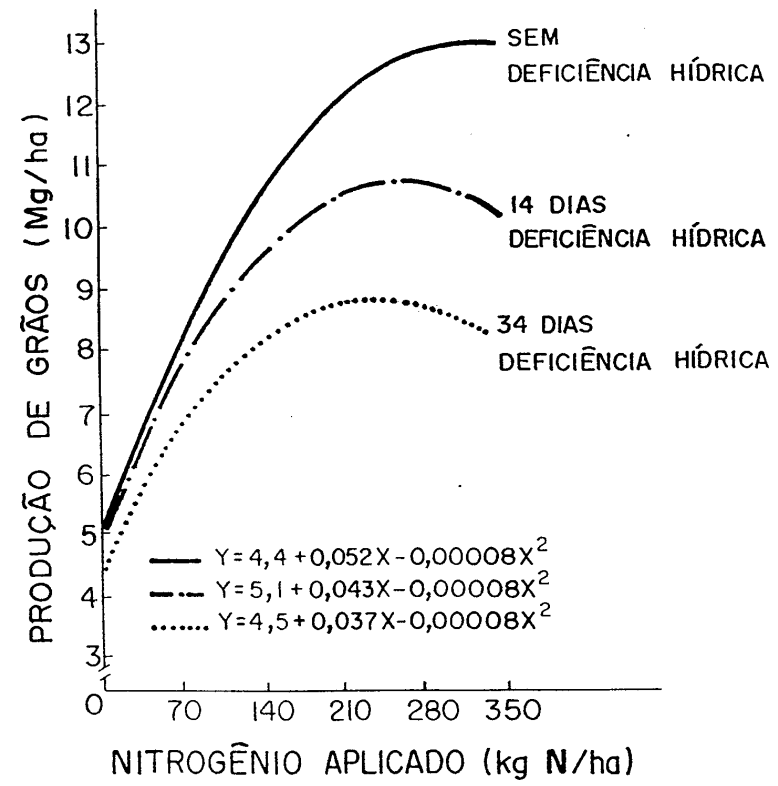

Figura 2. Produção de milho com diferentes doses de N, em condições normais e de deficiência hídrica (adaptado de Eck, 1984)

de deficiência hídrica, principalmente a alto níveis de nitrogênio; da mesma maneira, a Figura 3 mostra a resposta da cultura de arroz de sequeiro à aplicação de $\mathrm{P}$, com e sem deficiência hídrica. No ano normal de precipitação a produtividade atingiu aproximadamente 5 t/ha com a aplicação de $150 \mathrm{kgP}_{2} \mathrm{O}_{5} /$ ha e a utilização de $\mathrm{P}$ neste caso foi alta, mas quando a cultura sofreu, em média, 40 dias de deficiência hídrica, começando no início da emissão do primórdio floral a até dez dias após a floração, a produtividade foi significativamente reduzida, não havendo contribuição da adubação fosfatada. A eficiência de P diminuiu

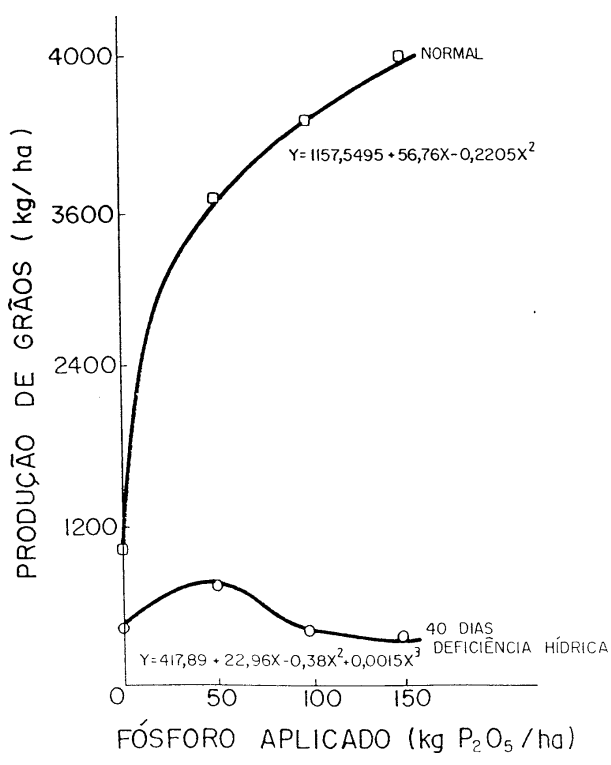

Figura 3. Produção de arroz de sequeiro com diferentes doses de fósforo aplicado a lanço, em condições normais e de deficiência hídrica (adaptado de Fageria, 1980)

neste caso, de forma significativa. A Figura 4 mostra a resposta de arroz de sequeiro à aplicação de $\mathrm{K}$, com e sem deficiência hídrica em torno da floração. A produção de grãos diminuiu significativamente com 14 dias de deficiência hídrica e, em conseqüência, houve diminuição da eficiência de utilização de K. Solo

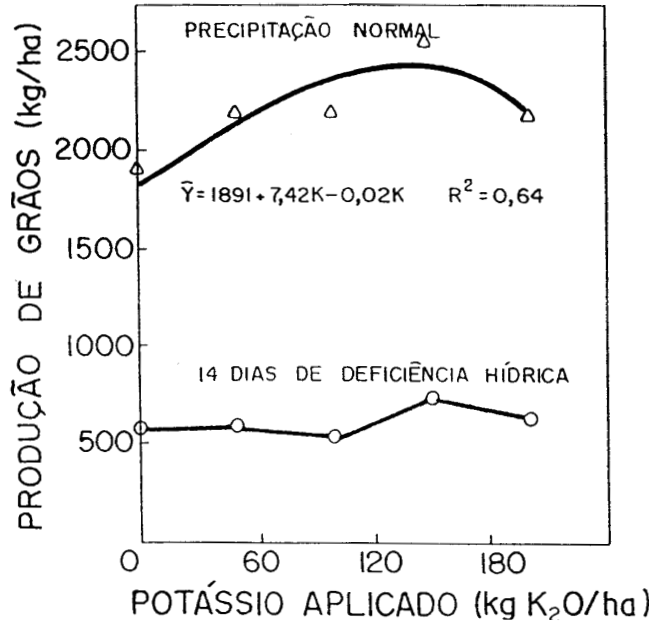

Figura 4. Produção de arroz de sequeiro com diferentes doses de potássio, em condições normais e de deficiência hídrica (adaptado de Fageria et al., 1990a)

A disponibilidade de nutrientes pelas plantas é influenciada pelas propriedades físicas, químicas e biológicas do solo. Em razão do assunto ser vasto, neste item são discutidas somente algumas propriedades químicas do solo.

\section{pH do solo}

$\mathrm{O}$ pH do solo é uma das propriedades químicas mais importantes na determinação da disponibilidade de nutrientes para as plantas. A disponibilidade de fósforo é altamente dependente do $\mathrm{pH}$. O principal mecanismo de fixação de fósforo sob baixo $\mathrm{pH}$ é a precipitação de fósforo com $\mathrm{Al}$ e Fe; em $\mathrm{pH}$ alto a precipitação ocorre principalmente pela formação de fosfatos cálcicos insolúveis; em geral, a disponibilidade de Mn, $\mathrm{Fe}, \mathrm{Cu}$ e $\mathrm{Zn}$ aumenta com o aumento da acidez do solo e a 
disponibilidade de Mo e B diminui (Bohn et al., 1979).

Se o pH não estiver na faixa adequada, a deficiência ou toxidez nutricional poderá ocorrer e a produção das culturas ser prejudicada e, conseqüentemente, a eficiência nutricional diminuir. O sistema solo-planta é dinâmico, sendo difícil definir o pH ótimo para várias culturas anuais, mas a maioria das culturas pode produzir bem em solo com $\mathrm{pH}$ em torno de 6 (Fageria et al., 1990b). A Tabela 5 mostra a resposta de algumas culturas anuais ao pH do solo de cerrado. Com esta tabela está bem claro que a cultura de arroz é mais tolerante à acidez do solo e a cultura de feijão mais suscetível entre as espécies avaliadas. Na média, o pH do solo de cerrado está em torno de 5 (Lopes, 1983). Para se elevar este $\mathrm{pH}$ para 6 é necessária a aplicação de aproximadamente $12 \mathrm{t} \mathrm{ha}^{-1}$ de calcário (Figura 5).

\section{Teor de matéria orgânica}

Tabela 5. Peso da matéria seca da parte aérea e de raízes (g/quatro plantas) de arroz, trigo, milho, feijão e caupi sob diferentes $\mathrm{pH}$ em latossolo vermelho-escuro de cerrado

\begin{tabular}{|c|c|c|c|c|c|c|c|c|c|c|}
\hline \multirow{2}{*}{$\mathrm{pH}$} & \multicolumn{2}{|c|}{ Arroz } & \multicolumn{2}{|c|}{ Trigo } & \multicolumn{2}{|c|}{ Milho } & \multicolumn{2}{|c|}{ Feijão } & \multicolumn{2}{|c|}{ Caupi } \\
\hline & Raízes & P. Aérea & Raízes & P. Aérea & Raízes & P. Aérea & Raízes & P. Aérea & Raízes & P. Aérea \\
\hline 4,1 & 2,25 & 12,43 & 4,85 & 11,50 & 12,08 & 26,63 & 1,90 & 8,60 & 2,28 & 8,53 \\
\hline 4,7 & 1,45 & 12,05 & 10,05 & 15,25 & 10,58 & 26,70 & 3,58 & 15,08 & 2,15 & 10,13 \\
\hline 5,3 & 1,18 & 11,33 & 11,78 & 13,75 & 11,28 & 29,03 & 4,67 & 15,88 & 2,28 & 9,65 \\
\hline 5,9 & 1,28 & 10,48 & 11,88 & 14,75 & 9,13 & 28,93 & 5,40 & 16,88 & 2,38 & 9,60 \\
\hline 6,6 & 1,03 & 8,83 & 10,98 & 15,30 & 10,93 & 24,43 & 4,73 & 18,38 & 2,23 & 9,48 \\
\hline 7,0 & 0,90 & 9,08 & 11,08 & 13,25 & 10,18 & 30,18 & 3,80 & 15,40 & 1,83 & 8,38 \\
\hline Teste F & $* *$ & $* *$ & $* *$ & ns & ns & ns & $* *$ & $* *$ & ns & $*$ \\
\hline Linear & $* *$ & ns & $* *$ & $\mathrm{~ns}$ & ns & ns & $* *$ & $* *$ & ns & $*$ \\
\hline Quadrática & $* *$ & $* *$ & ns & $\mathrm{ns}$ & ns & ns & ns & $* *$ & sn & $*$ \\
\hline
\end{tabular}

*, **, ns - significativo a 5 e $1 \%$ de probabilidade e não significativo, respectivamente

Fonte: Fageria et al. (1997)

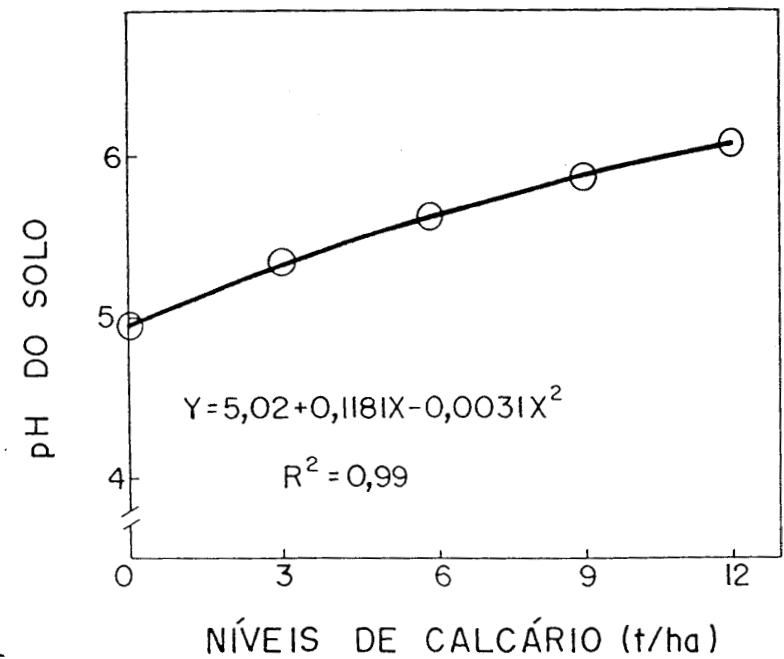

Figura 5. Influência da aplicação de calcário no $\mathrm{pH}$ do solo, aproximadamente seis meses após a aplicação em solo de cerrado (adaptado de Fageria, 1989)

A matéria orgânica exerce uma influência muito grande sobre as propriedades físicas, químicas e biológicas do solo e, em conseqüência, sobre a eficiência nutricional. As influências mais evidentes podem ser delineadas como (Fageria, 1989):

- melhoria das propriedades físicas, que auxiliam na granulação e na redução da plasticidade e da coesão do solo

- aumento da capacidade de absorção de cátions

- fornecimento de energia para a atividade dos microrganismos do solo
- redução da erosão

- estabilização da temperatura do solo, melhorando as condições ambientais para o desenvolvimento das raízes

- aumento da capacidade de retenção de água, o que tem acentuada importância para as regiões dos cerrados, onde existem problemas de veranicos durante o ciclo das culturas - diminuição da toxidez de Al em solo ácido.

As três práticas de manejo mais correlacionadas ao aumento ou manutenção da matéria orgânica no solo, são: I) manter a fertilidade do solo ao nível adequado na produção das culturas; II) uso de rotação das culturas apropriadas; e III) uso de cultivo mínimo na produção de culturas anuais.

\section{Toxidez de alumínio}

O alumínio trocável é um cátion importante nos solos ácidos e ocupa grande parte da capacidade de troca de cátions efetiva desses solos (Camargo \& Furlani, 1989). O principal fator que controla a concentração do Al na solução do solo é o pH. A solubilidade do Al é baixa ou nula, com $\mathrm{pH}$ na faixa de 5,5 a 7,5, onde ocorre precipitação e fica relativamente insolúvel como $\mathrm{Al}$ (OH) (Mclean, 1976). A solubilidade do Al aumenta em pH abaixo 5,5 e acima de 7,5. A toxidez de alumínio é particularmente severa em $\mathrm{pH}$ abaixo

de 5,0, mas pode ocorrer em solos com pH de até 5,5. Para determinada planta, o pH crítico das concentrações tóxicas depende de vários fatores do solo, como minerais de argila predominantes, níveis de matéria orgânica e concentrações de outros cátios, ânions e sais totais.

O excesso de alumínio inibe a formação normal da raiz, interfere nas reações enzimáticas e interfere na absorção de nutrientes (Foy, 1974) com reflexos negativos na produtividade. Os dados da Tabela 6 ilustram os efeitos do Al na produção de matéria seca e grãos de arroz e feijão em solo de várzea do

Tabela 6. Produção de matéria seca e grãos (g/três plantas) de arroz e feijão sob diferentes níveis de $\mathrm{Al}$ em solo de várzea

\begin{tabular}{cccccc}
\hline & \multicolumn{2}{c}{ Arroz } & & \multicolumn{2}{c}{ Feijão } \\
\cline { 5 - 6 } Nível de Al $_{\text {mmol }_{\mathrm{c}} / \mathrm{dm}^{3}}$ & $\begin{array}{c}\text { Peso da } \\
\text { matéria seca } \\
\text { da parte áerea }\end{array}$ & grãos & & $\begin{array}{c}\text { peso da } \\
\text { matéria seca } \\
\text { da parte aérea }\end{array}$ & grãos \\
\hline 0,0 & 29,95 & 2,85 & 4,43 & 4,74 \\
0,3 & 26,23 & 2,13 & & 4,05 & 4,08 \\
1,0 & 33,58 & 2,33 & & 4,45 & 5,37 \\
2,3 & 29,90 & 1,80 & & 4,20 & 5,22 \\
10,3 & 35,80 & 2,95 & & 1,93 & 2,49 \\
38,3 & 28,70 & 4,17 & & 0 & 0 \\
Teste F & ns & $*$ & & $* *$ & $* *$ \\
Linear & ns & $*$ & & $* *$ & $* *$ \\
Quadrática & $\mathrm{ns}$ & ns & $* *$ & $*$ \\
\hline
\end{tabular}

*, **, ns - significativo a 5 e $1 \%$ de probabilidade, respectivamente, e não significativo

Fonte: Fageria et al. (1997) 
Estado de Goiás e mostram, também, que a cultura de feijão é suscetível à toxidez de $\mathrm{Al}$ e a cultura do arroz é tolerante. A diferença entre espécie e cultivar de mesma espécie em relação à sua tolerância a toxidez de $\mathrm{Al}$ é discutida em vários artigos na literatura (Fageria, 1984a; Fageria et al., 1988a; Foy 1974, 1992; Taylor, 1988; Hai et al., 1989; Fageria \& Baligar, 1993). De acordo com Foy (1992) a porcentagem de saturação de Al no solo é o melhor critério de avaliação do grau de toxidez desse elemento para as plantas. O nível de saturação de $\mathrm{Al}$ maior que $60 \%$ é considerado tóxico para a maioria das culturas. Para as culturas suscetíveis como feijão, soja, algodão, aveia e alfafa, o nível crítico situa-se entre 10 e $20 \%$; este critério é mais válido para solos de baixo e médio teores de matéria orgânica, como os de cerrados em que, em condições naturais, a matéria orgânica é pouco ativa.

\section{Deficiência de fósforo}

A deficiência de $\mathrm{P}$ é um dos principais fatores que limitam a produção agrícola em solos ácidos. Aproximadamente $82 \%$ da área da América Tropical são deficientes em fósforo (Sanchez $\&$ Salinas 1981). De acordo com Malavolta (1976) $75 \%$ dos solos brasileiros têm teores baixos de fósforo e, entre os nutrientes N, P e K, o P é o mais usado em adubação no Brasil (Raij, 1991). Explica-se esta situação pela carência generalizada de fósforo nos solos brasileiros e, também, porque o elemento tem forte interação com o solo. A fixação de $\mathrm{P}$ em latossolo vermelho-escuro de cerrado chega a até $90 \%$ (Fageria \& Barbosa Filho, 1987). A resposta de algumas culturas anuais à aplicação de N, P e K em solo de cerrado é apresentada na Figura 6. Com base em dados de parte aérea e de raízes, pode-se concluir que entre os três macronutrientes, o P é o nutriente mais limitante no crescimento dessas culturas e que, em quantidades adequadas, estimula o desenvolvimento radicular, o que certamente está relacionado à absorção de nutrientes e, consequientemente, à eficiência nutricional.
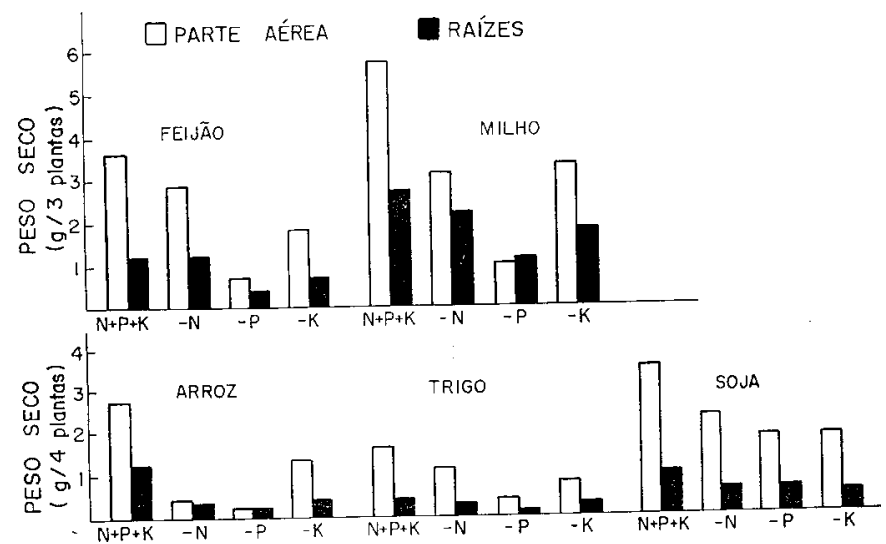

Figura 6. Resposta de N, P e K a algumas culturas anuais, em solo de cerrado (adaptado de Fageria, 1994)

\section{Deficiência de cálcio e magnésio}

A deficiência de $\mathrm{Ca}$ e $\mathrm{Mg}$ é relatada em solos ácidos em várias parte do mundo. Moore Junior \& Patrick (1989) concluíram que a deficiência de Ca e $\mathrm{Mg}$ em solos ácidos-sulfato é responsável pela diminuição da produtividade de arroz na Tailândia. Em um estudo de 17 solos da Austrália, Bruce et al. (1988) relataram que todos se apresentavam com deficiência de Ca no subsolo. Njhon et al. (1987) destacaram que a deficiência de Ca é a principal causa da diminuição da produtividade de milho em ultissol da Nigéria. Raij (1981) observou que no Brasil é preconizada a elevação dos teores de cálcio mais magnésio a 20 ou $30 \mathrm{mmol} / \mathrm{dm}^{3}$ através de calagem, mesmo quando os solos apresentam teores baixos de alumínio. A justificativa seria o fornecimento do cálcio e do magnésio como nutrientes. Galrão \& Lopes (1979) relatam, em levantamento sobre deficiências nutricionais em solos de cerrados, que dentre 512 amostras de solos sob vegetação de cerrado $96 \%$ apresentavam teores de cálcio abaixo do nível crítico $\left(15 \mathrm{mmol} \mathrm{kg}^{-1}\right)$ e $90 \%$ apresentaram teores de $\mathrm{Mg}$ abaixo do nível crítico $\left(5 \mathrm{mmol}_{\mathrm{c}} \mathrm{kg}^{-1}\right)$.

\section{Salinidade}

Salinização é o processo pelo qual sais solúveis se acumulam na zona radicular do solo. Os sais solúveis que efetivamente contribuem para salinizar o solo consistem, normalmente, das várias proporções de cátions de cálcio, magnésio, sódio e dos ânions cloreto, sulfato, bicarbonato e, às vezes, carbonato (Allison, 1964). A salinização ocorre em duas regiões distintamente diferentes. Em regiões litorâneas, a salinização é conseqüência da inundação do solo pela água salgada dos mares ou oceanos. Nas regiões áridas e semi-áridas, além dos sais introduzidos pela água de irrigação, os solos podem conter sais cuja origem está associada à sua geoquímica.

A água de irrigação contém sais solúveis e seu uso constante, na ausência de lixiviação, faz com que o sal se deposite na zona do sistema radicular devido à evaporação. A drenagem superficial inadequada conduz, com freqüência, a uma concentração de sais no interior da bacia, ao invés da sua descarga no mar.

Solos salinos existem em todas as partes do mundo (Tabela 7); no Brasil, as áreas de solos afetadas por sais em sete Estados do Nordeste, segundo o Serviço Nacional de Levantamento e Conservação de Solos, atingem aproximadamente 9,11 milhões de hectares (Pereira, 1983). O efeito adverso da salinidade na absorção e utilização de nutrientes está relacionado com o aumento da pressão osmótica na solução do solo, com a acumulação de certos íons no tecido vegetal, em concentrações tóxicas, e diminuição no crescimento do sistema radicular (Allison, 1964; Pessarakali et al., 1989a, 1989b; Postal, 1990). De acordo com Fageria (1985) o aumento da salinidade de 0,29 $\mathrm{dSm}^{-1}$ a $15 \mathrm{dSm}^{-1}$ diminui os teores de $\mathrm{P}$ e K na planta de arroz. $\mathrm{O}$ mesmo autor relatou que o desbalanço nutricional devido à salinidade é a principal causa na redução da produtividade do arroz em solos salinos.

Tabela 7. Distribuição de solos salinos em várias partes do mundo

\begin{tabular}{lrrr}
\hline \multirow{2}{*}{ Região } & \multicolumn{3}{c}{ Área (em 1000 hectares) } \\
\cline { 2 - 4 } & Salino & Sódico & \multicolumn{1}{c}{ Total } \\
\hline América do Norte & 6191 & 9564 & 15755 \\
México e América Central & 1965 & - & 1965 \\
América do Sul & 69410 & 59573 & 128983 \\
África & 53492 & 29946 & 80438 \\
Ásia do Sul & 83312 & 1798 & 85110 \\
Ásia do Norte & 91621 & 120065 & 211686 \\
Ásia Sul-Leste & 19983 & - & 19983 \\
Austrália e Nova Zelândia & 17359 & 339971 & 357330 \\
& & & \\
Total & 343333 & 557917 & 901250 \\
\hline
\end{tabular}

Fonte: Lal et al. (1989) 


\section{aPlanta}

Os principais fatores da planta que afetam a eficiência nutricional são: variabilidade genética, crescimento das raízes, micorrizas, fixação biológica de nitrogênio, alelopatia, doenças, pragas e plantas invasoras.

\section{Variabilidade genética}

A variabilidade genética da planta refere-se à característica hereditária de uma espécie vegetal ou cultivar que apresenta diferença de crescimento ou produção em comparação com outra espécie ou cultivar, sob condições de ambiente ideais ou adversas (Fageria, 1989). Vários trabalhos evidenciam o comportamento diferencial entre espécies ou cultivares da mesma espécie na absorção e utilização de: N (Fageria \& Barbosa Filho, 1982; Messmer et al., 1984; Sinclair \& Horie, 1989; Wuest \& Cassman, 1992; Youngquist et al., 1992); P (Fageria \& Barbosa Filho, 1981; Fageria et al., 1988b, 1988c; Martinez et al., 1993a, 1993b); K (Glass \& Perley, 1980; Siddiqi et al., 1987; Woodend et al., 1987); Ca (Fageria, 1984b) Mg (Clark, 1982; Fageria \& Morais, 1987); Fe (Fageria et al., 1990a; Hughes et al., 1992); e Zn (Clark, 1978; Peaslee et al., 1981; International Rice Research Institute, 1989). Devido à exigência nutricional bem variável entre espécies e variedades da mesma espécie, é comum observarse produtividades diferentes sob as mesmas condições de fertilidade do solo (Tabela 8).

Tabela 8. Produção de grãos (kg/ha) por genótipos de arroz de sequeiro sob diferentes níveis de fertilidade

\begin{tabular}{|c|c|c|c|c|c|}
\hline \multirow{2}{*}{ Genótipos } & \multicolumn{3}{|c|}{ Niveis de fertilidade } & \multirow{2}{*}{ Média } & \multirow[t]{2}{*}{$\mathrm{IEG}^{1}$} \\
\hline & Baixo & Médio & Alto & & \\
\hline Rio Paranaiba & $3533 a$ & $3666 a$ & $4125 a b$ & $3775 \mathrm{a}$ & 1,75 \\
\hline CNA7657 & $3450 \mathrm{a}$ & $3050 \mathrm{abc}$ & $3133 \mathrm{cdef}$ & $3211 a b c$ & 1,30 \\
\hline CNA7690 & $3391 \mathrm{ab}$ & $2983 \mathrm{abc}$ & $3541 b c$ & $3306 a b c$ & 1,44 \\
\hline CNA7061 & $3133 a b c$ & $2783 a b c$ & $2500 \mathrm{fg}$ & $2806 \mathrm{cde}$ & 0,94 \\
\hline CNA7677 & $2933 a b c$ & $3050 \mathrm{abc}$ & $2650 \mathrm{cdefg}$ & $2879 \mathrm{cde}$ & 0,93 \\
\hline CNA7706 & $2833 \mathrm{abc}$ & $2916 a b c$ & 2441defg & $2731 \mathrm{Cde}$ & 0,83 \\
\hline CNA7653 & $2800 \mathrm{abc}$ & $2566 \mathrm{bc}$ & $2575 \mathrm{dg}$ & $2647 \mathrm{cdef}$ & 0,86 \\
\hline CNA7704 & $2775 \mathrm{abc}$ & $3183 a b c$ & $3200 \mathrm{bcde}$ & $3053 \mathrm{bc}$ & 1,06 \\
\hline CNA7674 & $2758 \mathrm{abc}$ & $3008 \mathrm{abc}$ & $3558 b \mathrm{c}$ & $3108 \mathrm{abc}$ & 1,18 \\
\hline CNA7691 & $2691 \mathrm{abc}$ & $3308 a b$ & $2916 \mathrm{~cd}$ & $2972 b c d$ & 0,94 \\
\hline CNA7671 & $2516 \mathrm{abc}$ & $3033 \mathrm{abc}$ & $3358 \mathrm{bcd}$ & $2969 \mathrm{bcd}$ & 1,01 \\
\hline CNA7645 & $2391 \mathrm{abc}$ & $3425 \mathrm{ab}$ & $5041 \mathrm{a}$ & $3619 \mathrm{ab}$ & 1,45 \\
\hline CNA7754 & $1883 a b c$ & $2416 \mathrm{bc}$ & $2416 \mathrm{efg}$ & $2239 \mathrm{ef}$ & 0,54 \\
\hline CNA7726 & $1741 \mathrm{bc}$ & $2141 \mathrm{c}$ & $2250 \mathrm{fg}$ & $2044 \mathrm{f}$ & 0,47 \\
\hline CNA7755 & $1516 c$ & $2950 \mathrm{abc}$ & $2650 \mathrm{cdefg}$ & $2372 \mathrm{def}$ & 0,48 \\
\hline Média & 2689 & 2965 & 3090 & 2915 & 1,01 \\
\hline Teste $\mathbf{F}$ & $* *$ & $* *$ & $* *$ & $* *$ & \\
\hline C.V. $\%$ & 21 & 12 & 10 & 14 & \\
\hline
\end{tabular}

** Significativo a $1 \%$ de probabilidade. Os valores seguidos da mesma letra na mesma coluna não diferem, em nível de $5 \%$ de probabilidade pelo teste de Tukey

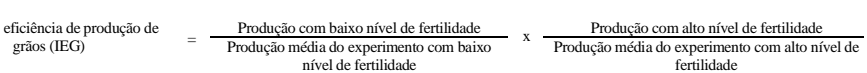

Fonte: Fageria et al. (1994)

Resultados de um estudo em casa de vegetação, realizado na Embrapa Arroz e Feijão mostraram a diferença da resposta de cultivares de arroz irrigado à aplicação de potássio em solo gley pouco úmido, de várzea (Figura 7); existe uma diferença muito grande entre duas cultivares na produção, principalmente em altos níveis de potássio.

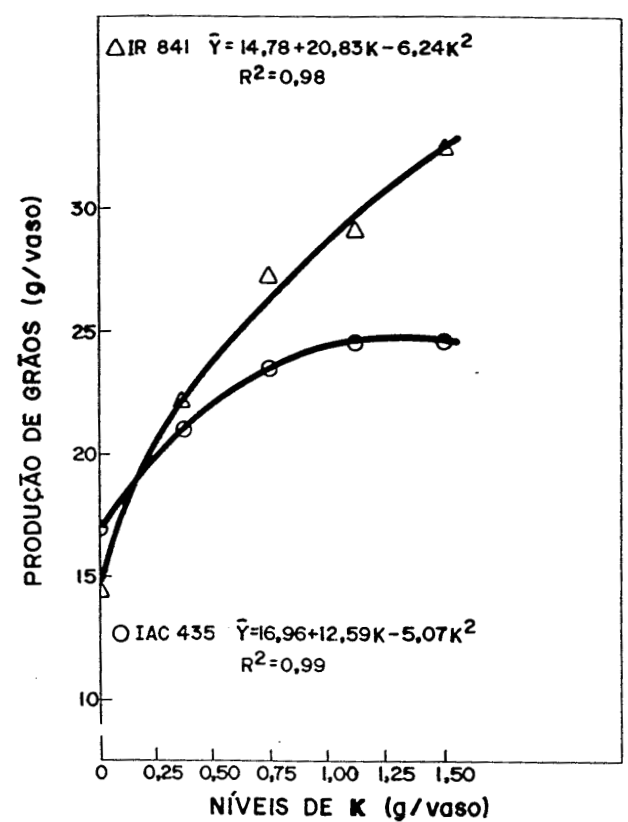

Figura 7. Influência de níveis de $\mathrm{K}$ na produção de duas cultivares de arroz irrigado (adaptado de Fageria, 1989)

\section{Crescimento do sistema radicular}

O sistema radicular das plantas, quando bem desenvolvido, é considerado fator importante na produção. As principais funções das raízes das plantas são a absorção de nutriente e água do solo e o suporte mecânico da planta. A diferença varietal no desenvolvimento do sistema radicular das culturas anuais é relatada em vários estudos (Caradus, 1981, Ennos, 1985). Outros fatores que afetam o sistema radicular são níveis de nutrientes no solo, preparo do solo, tipo do solo, umidade do solo e infestação por doenças e pragas.

O sistema radicular extensivo explora maior volume do solo e absorve mais nutrientes e água e, conseqüentemente, aumenta a eficiência nutricional.

\section{Fixação biológica de nitrogênio}

A crise mundial de energia e a crescente produção com a preservação do meio ambiente proporcionaram, no mundo inteiro, interesse cada vez maior por todos os aspectos da fixação biológica do nitrogênio atmosférico. A fixação biológica de nitrogênio $\left(\mathrm{N}_{2}\right)$ pode ser simbiótica ou assimbiótica. A simbiótica refere-se ao processo em que o microrganismo fixa o nitrogênio, enquanto cresce em associação com a planta hospedeira com benefício mútuo; a fixação assimbiótica é realizada por bactéria de vida livre no solo e a fixação simbiótica é muito superior à da não-simbiótica. A quantidade de nitrogênio fixada depende de vários fatores, como tipo de leguminosa, eficiência do Rhizobium, condições ambientais (temperatura, intensidade da radiação solar, $\mathrm{pH}$ do solo) e fertilizante do solo.

\section{Micorrizas}

A associação simbiótica entre certos fungos do solo e raízes das plantas é denominada micorriza; com esta associação, normalmente ambos os componentes são beneficiados. A infecção de micorrizas aumenta a capacidade das raízes das plantas na absorção de N, P, K, Ca, S, Fe Cu e Zn (Safir, 1980). Entre os nutrientes, a absorção de fósforo é o mais importante. Os fungos não solubilizam o fosfato, mas permitem que as plantas associadas absorvam mais fosfato pela exploração de um volume 
maior de solo e aumento dos sítios de absorção de maior afinidade por este nutriente, nas raízes micorrizadas (Cress et al., 1979; Mosse, 1981; Lopes et al., 1983).

\section{Alelopatia}

Rice (1974) define alelopatia como o efeito nocivo de uma planta sobre ela mesma ou sobre outra planta, através da produção de substâncias químicas. A liberação de substância química na rizoosfera é feita, geralmente, através de excreções das raízes ou através da decomposição dos restos culturais (Rose et al., 1984). Os restos culturais incorporados ao solo podem produzir aleloquímicos que inibem a germinação da semente e o crescimento inicial das plantas (Martin et al., 1990). A produção de aleloquímicos é maior em temperaturas mais altas $\left(20-25^{\circ} \mathrm{C}\right)$ em comparação à baixa temperatura (Jessop \& Stewart, 1983). O baixo $\mathrm{pH}$ do solo também favorece a produção de fitotoxinas mas, uma vez que as toxinas foram produzidas, podem ficar ativas sobre larga faixa de pH. Em adição ao efeito negativo dos aleloquímicos no crescimento da planta, eles podem inibir a absorção de nutrientes pela cultura afetada (Bhowmik \& Doll, 1984). Ruschel \& Paula (1994) observaram alelopatia e autotoxicidade em arroz de sequeiro em solo de cerrado. Os mesmos autores relatam que extrato de macerado de raiz de arroz de sequeiro, verdes ou secos, inibiram a germinação. A concentração de solução do complexo rizosfera em solo onde o arroz se desenvolvia diminuiu a produção de arroz, demonstrando que a planta excreta a substância inibidora de seu desenvolvimento. Plantas com alelopatia apresentam diminuição de pelos radiculares (Ruschel \& Paula, 1994).

\section{Doenças, pragas e plantas daninhas}

Doenças e pragas afetam a área foliar da planta, que reduz o processo de fotossíntese. Devido à redução da fotossíntese, diminui a produtividade e, conseqüentemente, a utilização de nutrientes. As plantas daninhas competem com as plantas cultivadas por nutrientes, água e luz. Devido a esta competição, diminui a produtividade e, em conseqüência, a absorção e utilização de nutriente.

\section{MECANISMOS DO USO EFICIENTE DE NUTRIENTES}

Existem vários mecanismos e processos na planta que contribuem para o uso eficiente de nutrientes. Esses mecanismos e processos são resumidos por Fageria \& Baligar (1993) e estão relacionados com as características morfológicas e fisiológicas desejáveis.

- Características morfológicas

Sistema radicular eficiente

Alta relação entre raízes e parte áerea

Sistema radicular extensivo, explorando maior volume de solo

Colonização do sistema radicular por micorrizas e bactérias que fixam o nitrogênio

- Características fisiológicas

Habilidade do sistema radicular na modificação da rizosfera para superar baixos níveis de nutrientes

Maior eficiência de absorção ou de utilização de nutrientes
Capacidade de manter o metabolismo normal com baixo teor de nutrientes nos tecidos

Alta taxa de fotossíntese.

\section{RECOMENDAÇÕES ESPECÍFICAS PARA O AUMENTO DA EFICIÊNCIA NUTRICIONAL}

Com a adoção de práticas apropriadas de manejo do solo e planta, pode-se aumentar a produtividade e, conseqüentemente, a eficiência nutricional. Algumas práticas são enumeradas a seguir:

- preparo adequado para cada tipo de solo

- plantio na época certa

- tratamento de semente com fungicidas e inseticidas para controle de doenças e pragas

- uso adequado de adubação e calagem

- uso adequado de espaçamento e densidade das plantas

- uso de sementes de boa qualidade

- uso de cultivar de alto potencial de produtividade e resistente às doenças

- cobertura de $\mathrm{N}$ no estádio apropriado da cultura, em quantidade adequada

- controle de doenças, pragas e invasoras

- uso apropriado de rotação de culturas

- controle de erosão

- manutenção do teor de matéria orgânica em nível adequado

- manutenção adequada da umidade do solo em culturas irrigadas e, existindo viabilidade, aplicação de irrigação suplementar durante o período de deficiência hídrica na época chuvosa, para culturas de sequeiro

- incorporação de restos culturais para reciclagem de nutrientes

- uso de adubação verde ou esterco animal

- colheita na época apropriada.

\section{CONCLUSÕES}

1. A eficiência de utilização de nutrientes é definida de várias maneiras na literatura, mas os componentes mais comuns da eficiência são absorção e utilização de nutrientes; em solo com baixa fertilidade, a eficiência de utilização é mais importante em comparação com a eficiência de absorção na produção de grãos; em solo de alta fertilidade, ambas as eficiências são importantes na produção das culturas.

2. A deficiência de fósforo é mais limitante na produção das culturas anuais em solos ácidos, como os de cerrado, em comparação a outros nutrientes; portanto, é necessário mais atenção para aumentar a eficiência deste nutriente na produção das culturas.

3. A revisão de literatura mostra que existe variabilidade genética entre espécies e cultivares da mesma espécie, na absorção e utilização de nutrientes; entretanto, é preciso se conhecer melhor os mecanismos de absorção e utilização de nutrientes e, também, a natureza e herança da eficiência.

4. Em experimento de campo, a produção de grãos é o melhor parâmetro para avaliação da eficiência nutricional em culturas anuais; em caso de experimento em condições controladas, tanto a produção de grãos como a produção de matéria seca podem ser usadas como parâmetro de avaliação da eficiência nutricional. 


\section{REFERÊNCIAS BIBLIOGRÁFICAS}

ALLISON, L.E. Salinity in relation to irrigation. Advances in Agronomy, San Diego, v.16, p.139-178, 1964.

BAILIAN, L.; McKEAND, S.E.; ALLEN, H.L. Genetic variation in nitrogen use efficiency of lablolly pine seedlings. Forest Science, London, v.37, p.613-628, 1991.

BALIGAR, V.C.; BENNETT, O.L. NPK-fertilizer efficiency a situation analysis for the tropics. Fertilizer Research, Dordrecht, v.10, p.147-164, 1986.

BHOWMIK, P.C.; DOLL, J.D. Allelopathic effects of annual weed residues on growth and nutrient uptake of corn and soybeans. Agronomy Journal, Madison, v.76, p.383-388, 1984.

BOHN, H.L.; McNEAL, B.L.; O'CONNOR, G.A. Soil chemistry. New York: John Wiley, 1979. 329p.

BRUCE, R.C.; WARREL, L.A.; EDWARDS, D.G.; BELL, L.C. Effects of aluminum and calcium in the soil solution of acid soil on root elongation of soybean. Australian Journal of Agricultural Research, Melbourne, v.39, p.319-338, 1988.

CAMARGO, O.A.; FURLANI, P.R. Alumínio no solo: concentração, especificação e efeito no desenvolvimento radicular. In: SIMPÓSIO AVANÇADO DE SOLOS E NUTRIÇÃO DE PLANTAS, 2., 1989, Piracicaba. Anais... Piracicaba: ESALQ/USP, 1989. p.45-69.

CAMPBELL, C.A.; ZENTNER, R.P.; SELLES, F.; McCONKEY, B.G.; DYCK, F.B. Nitrogen management for spring wheat grown annually on zero tillage: yield and nitrogen-use efficienty. Agronomy Journal, Madison, v.85, p.107-114, 1993.

CARADUS, J.R. Root growth of white clover (Trifolium repens L.) lines in glas-fronted containers. New Zealand Journal of Agricultural Research, Wellington, v.24, p.43-54, 1981.

CLARK, R.B. Differential response of maize inbreds to Zn. Agronomy Journal, Madison, v.70, p.1057-1060, 1978.

CLARK, R.B. Plant response to mineral element toxicity and deficiency. In: CHRISTIANSEN, M.N.; LEWIS, C.F., ed. Breeding plants for less favorable environment. New York: John Wiley, 1982. p.71-142.

COELHO, A.M.; FRANÇA, G.E.; BAHIA, A.F.C.; GESEDES, G.A.A. Balanço de nitrogênio $15_{\mathrm{N}}$ em um latossolo vermelhoescuro, sob vegetação de cerrado, cultivado com milho. Revista Brasileira de Ciência do Solo, Campinas, v.15, p.187-193, 1991.

COOKE, G.W. Maximizing fertilizer efficiency by overcoming constraints to crop growth. Journal of Plant Nutrition, New York, v.10, p.1357-1369, 1987.

CRASWELL, E.T.; GODWIN, D.C. The efficiency of nitrogen fertilizers applied to cereals in different climates. In: TINKER, P.B.; LAUCHI, A., ed. Advances in plant nutrition. New York: Praeger, 1984. p.1-55.

CRESS, W.A.; THRONEBERRY, G.O.; LINDSEY, D.L. Kinetics of phosphorus absorption by mycorrhizal and nonmycorrhizal tomato roots. Plant Physiology, Rockville, v.64, p.484-487, 1979.

DENT, F.J. Major production systems and soil related constraints in southeast Asia. In: INTERNATIONAL RICE RESEARCH INSTITUTE (Los Baños, Filipinas). Priorities for alleviating food production in the tropics. Los Baños, 1980. p.79-106.
ECK, H.V. Irrigated corn yield response to nitrogen and water. Agronomy Journal, Madison, v.76, p.421-428, 1984.

EDMOND, J.B.; SENN, T.L.; ANDREWS, F.S.; HALFACRE, R.G. Fundamentals of horticulture. 4.ed. Toronto: McGraw-Hill, 1975. 1v.

ENNOS, R.A. The significance of genetic variation for root growth within a natural population of white clover (Trifolium repens L.). Journal of Ecology, Oxford, v.73, p.615-624, 1985.

FAGERIA, N.K. Adubação e nutrição mineral da cultura de arroz. Rio de Janeiro: EMBRAPA/Campus, 1984a. 341p.

FAGERIA, N.K. Deficiência hídrica em arroz de cerrado e resposta ao fósforo. Pesquisa Agropecuária Brasileira, Brasília, v.15, n.3, p.259-285, 1980.

FAGERIA, N.K. Maximizing crop yields. New York: Marcel Dekker, 1992. 274p.

FAGERIA, N.K. Resposta de cultivares de arroz a aplicação de calcário em solo de cerrado. Pesquisa Agropecuária Brasileira, Brasília, v.19, n.7, p.883-889, 1984b.

FAGERIA, N.K. Salt tolerance of rice cultivars. Plant and Soil, Dordrecht, v.88, p.237-243, 1985.

FAGERIA, N.K. Soil acidity affects availability of nitrogen, phosphorus and potassium. Better Crops International, Atlanta, v.10, p.8-9, 1994.

FAGERIA, N.K. Solos tropicais e aspectos fisiológicos das culturas. Brasília: EMBRAPA-CNPAF, 1989. 425p.

FAGERIA, N.K.; BALIGAR, V.C.; WRIGHT, R.J. Aluminum toxicity in crop plants. Journal of Plant Nutrition, New York, v.11, p.303-319, 1988a.

FAGERIA, N.K.; BALIGAR, V.C. Screening crop genotypes for mineral stresses. In: WORKSHOP ON ADAPTATION OF PLANTS TO SOIL STRESSES, 1993, Lincoln. Proceedings... Lincoln: University of Nebraska, 1993. p.142159.

FAGERIA, N.K.; BALIGAR, V.C.; EDWARD, D.G. Soil-Plant nutrient relationships at low $\mathrm{pH}$ stress. In: BALIGAR, V.C.; DUNCAN, R.R., ed. Crops as enhancers of nutrient use. New York: Academic Press, 1990b. p.475-507.

FAGERIA, N.K.; BALIGAR, V.C.; JONES, C.A. Growth and mineral nutrition of field crops. 2.ed. New York: Marcel Dekker, 1991. 624p.

FAGERIA, N.K.; BALIGAR, V.C.; WRIGHT, R.J. Nutrição de ferro das plantas: química e fisiologia da sua deficiência e toxicidade. Pesquisa Agropecuária Brasileira, Brasília, v.25, n.4, p.553-570, 1990a.

FAGERIA, N.K.; BARBOSA FILHO, M.P. Avaliação de cultivares de arroz para maior eficiência na absorção de fósforo. Pesquisa Agropecuária Brasileira, Brasília, v.16, n.6, p.777-782, 1981

FAGERIA, N.K.; BARBOSA FILHO, M.P. Avaliação preliminar de cultivares de arroz irrigado para maior eficiência de utilização de nitrogênio. Pesquisa Agropecuária Brasileira, Brasília, v.17, n.12, p.1709-1712, 1982.

FAGERIA, N.K.; BARBOSA FILHO, M.P. Phosphorus fixation in oxisol of central Brazil. Fertilizers and Agriculture, Paris, v.94, p.33-47, 1987.

FAGERIA, N.K.; MORAIS, O.P. Avaliação de cultivares de arroz na utilização de cálcio e magnésio em solo de cerrado. Pesquisa Agropecuária Brasileira, Brasília, v.22, n.7, p.667-672, 1987. 
FAGERIA, N.K.; MORAIS, O.P.; BALIGAR, V.C.; WRIGHT, R.J. Response of rice cultivars to phosphorus supply on an oxisol. Fertilizer Research, Dordrecht, v.16, p.195-206, 1988 b.

FAGERIA, N.K.; SANTANA, E.P.; CASTRO, E.M. de; MORAIS, O.P.; MOURA NETO, F.P. de. Resposta diferencial de linhagens de arroz de sequeiro à fertilidade do solo. In: CONFERÊNCIA INTERNACIONAL DE ARROZ PARA AMÉRICA LATINA E O CARIBE, 9., 1994, Goiânia. Resumos. Goiânia: EMBRAPA-CNPAF/CIAT, 1994. Resumo 63.

FAGERIA, N.K.; WRIGHT, R.J.; BALIGAR, V.C. Rice cultivar evaluation for phosphorus use efficiency. Plant and Soil, Dordrecht, v.111, p.105-109, 1988c.

FOY, C.D. Effects of aluminium on plant growth. In: CARSON, E.W., ed. The plant root and its environment. Charlottesville: University Press of Virginia, 1974. p.601642.

FOY, C.D. Soil chemical factors limiting plant root-growth. Advances in Soil Science, New York, v.19, p.97-149, 1992.

GALRÃO, E.Z.; LOPES, A.S. Deficiências nutricionais em solos de cerrado. In: SIMPÓSIO SOBRE O CERRADO, 5., 1979, Brasília. Anais... Brasília: Editerra, 1979. p.595-614.

GLASS, A.D.M.; PERLEY, J.E. Varietal differences in potassium uptake by barley. Plant Physiology, Rockville, v.65, p.160164, 1980.

GRAHAM, R.D. Breeding for nutritional characteristics in cereals. In: TINKER, P.B.; LAUCHI, A., ed. Advances in plant nutrition. New York: Praeger, 1984. p.57-102.

GRANT, R.F.; JACKSON, B.S.; KINIRY, J.R.; ARKIN, G.F. Water deficit timing effects on yield components in maize. Agronomy Journal, Madison, v.81, p.61-65, 1989.

HAI, T.V.; NGA, T.T.; LAUDELOUT, H. Effect of aluminum on the mineral nutrition of rice. Plant and Soil, Dordrecht, v.114, p.173-185, 1989.

HSAIO, T.C. Plant responses to water stress. Annual Review of Plant Physiology, Palo Alto, v.24, p.519-570, 1973.

HUGHES, D.F.; JOLLEY, V.D.; BROWN, J.C. Role of potassium in the iron-stress response mechanism of ironefficient oat. Soil Science Society of America Journal, Madison, v.56, p.830-835, 1992.

INTERNATIONAL RICE RESEARCH INSTITUTE (Los Baños, Filipinas). Annual Report for 1988. Los Baños, 1989. 646p.

ISRAEL, D.W.; RUFTY JUNIOR, T.W. Influence of phosphorus nutrition on phosphorus and nitrogen utilization efficiencies and associated physiological response in soybean. Crop Science, Madison, v.28, p.954-960, 1988.

JEN-HU, C. Chemical and agriculture: an ecological survey. Chicago: Aldine, 1968. v.1.

JESSOP, R.S.; STEWART, L.W. Effects of crop residues, soil type and temperature on emergence and early growth of wheat. Plant and Soil, Dordrecht, v.74, p.101-109, 1983.

LAL, R.; HALL, G.F.; MILLER, F.P. Soil degradation. I. Basic processes. Land Degradation \& Rehabilitation, New York, v.1, p.51-69, 1989.

LOBATO, E. Adubação fosfatada em solos da região CentroOeste. In: OLIVEIRA, A.J. de; LOURENÇO, S.; GOEDERT, W.J. Adubação fosfatada no Brasil. Brasília: EMBRAPA-DID, 1982. p.201-239.
LOPES, A.S. Solos sob “Cerrado”: características, propriedades e manejo. Piracicaba: Potafós, 1983. 162p.

LOPES, A.S.; GUILHERME, L.R.G. Uso eficiente de fertilizantes. In: SIMPÓSIO AVANÇADO DE SOLOS E NUTRIÇÃO DE PLANTAS, 2., 1989, Piracicaba. Anais... Campinas: Fundação Cargill, 1989. p.1-58.

LOPES, E.S.; SIQUEIRA, J.O.; ZAMBOLIM, L. Caracterização das micorrizas vesicular-arbusculares (MVA) e seus efeitos no crescimento das plantas. Revista Brasileira de Ciência do Solo, Campinas, v.7, p.1-19, 1983.

MALAVOLTA, E. Manual de química agrícola: nutrição de plantas e fertilidade do solo. São Paulo: Agronômica Ceres, 1976. 528p.

MARANVILLE, J.W.; CLARK, R.B.; ROSS, W.M. Nitrogen efficiency in grain sorghum. Journal of Plant Nutrition, New York, v.2, p.577-589, 1980.

MARTIN, V.L.; MCCOY, E.L.; DICK, W.A. Allelopathy of crop residues influences corn seed germination and early growth. Agronomy Journal, Madison, v.82, p.555-560, 1990.

MARTINEZ, H.E.P.; NOVAIS, R.F.; RODRIGUES, L.A.; SACRAMENTO, L.V.S. do. Comportamento de variedades de soja cultivadas em diferentes doses de fósforo. I. Cinética de absorção de fósforo e ajustes morfológicos da planta. Revista Brasileira de Ciência do Solo, Campinas, v.17, p.231-238, 1993a.

MARTINEZ, H.E.P.; NOVAIS, R.F.; SACRAMENTO, L.V.S. do; RODRIGUES, L.A. Comportamento de variedades de soja cultivadas sob diferente níveis de fósforo: II. Translocação do fósforo absorvido e eficiência nutricional. Revista Brasileira de Ciência do Solo, Campinas, v.17, p.239-244, 1993b.

MCLEAN, E.O. Chemistry of soil aluminum. Communication in Soil Science and Plant Analysis, New York, v.7, p.619-636, 1976.

MESSMER, M.J.; LAMBERT, R.J.; HAGEMAN, R.H. Classification of certain $\mathrm{N}$ traits as criteria for the identification of productive maize genotye. Crop Science, Madison, v.24, p.605-610, 1984.

MOLL, R.H.; KAMPRATH, E.J.; JACKSON, W.A. Analysis and interpretation of factors which contribute to efficiency of nitrogen utilization. Agronomy Journal, Madison, v.74, p.562-564, 1982.

MOORE JUNIOR, P.A.; PATRICK, W.H. Manganese availability and uptake of rice in acid sulfate soils. Soil Science Society of America Journal, Madison, v.53, p.104-109, 1989.

MOSSE, B. Vesicular-arbuscular mycorrhiza research for tropical agriculture. Hawai: Institute for Tropical Agriculture and Human Resources, 1981. 82p. (Research Bulletin, 194).

NESMITH, D.S.; RITCHIE, J.T. Short and long term responses of corn to a pre-anthesis soil water deficit. Agronomy Journal, Madison, v.84, p.107-113, 1992.

NICKELL, L.G. Sugarcane. In: ALVIN, P.T.; KOZLOWSKI, T.T., ed. Ecophysiology of tropical crops. New York: Academic Press, 1977. p.89-111.

NJHON, B.O.; ENWEZOR, W.O.; ONZENAKWE, B.I. Calcium deficiency identified as an important factor limiting maize growth in acid ultisols of Eastern Nigeria. Fertilizer Research, Dordrecht, v.14, p.113-124, 1987. 
PEASLEE, D.E.; ISARANGKURA, R.; LEGGET, J.E. Accumulation and translocation of zinc by two corn cultivars. Agronomy Journal, Madison, v.73, p.729-732, 1981.

PEREIRA, J.R. Solos salinos e sódicos. In: REUNIÃO BRASILEIRA DE FERTILIDADE DO SOLO, 15., 1982, Campinas. Acidez e calagem no Brasil. Campinas: Sociedade Brasileira de Ciência do Solo, 1983. p.129143.

PESSARAKALI, M.; HUBER, J.T.; JACKSON, T.C. Protein synthesis in green beans under salt stress whit two nitrogen sources. Journal of Plant Nutrition, New York, v.12, p.1361-1377, 1989a.

PESSARAKALI, M.; HUBER, J.T.; TUCKER, T.C. Protein synthesis in green beans under salt stress conditions. Journal of Plant Nutrition, New York, v.12, p.11051121, 1989b.

POSTAL, S. Saving water in agriculture. In: BROWN, L.R.; DURNING, A; FLAVIN, C; FRENCH, H; JACOBSON, J; LOWE, M., ed. State of the world. New York: W.W. Norton, 1990. p.39-58.

RAIJ, B. Van. Avaliação da fertilidade do solo. Piracicaba: Potafós, 1981. 142p.

RAIJ, B. Van. Fertilidade do solo e adubação. São Paulo: Agronômica Ceres/Potafós, 1991, 343p.

RICE, E.L. Allelopathy. New York: Academic Press, 1974. $353 p$.

ROSE, S.J.; BURNSIDE, O.C.; SPECHT, J.E.; SWISH, B.A. Competition and allelopathy between soybeans and weeds. Agronomy Journal, Madison, v.76, p.523-528, 1984.

RUSCHEL, A.P.; PAULA, M.M. de. Alelopatia e autotoxidade em arroz de sequeiro. In: CONFERÊNCIA INTERNACIONAL DE ARROZ PARA AMÉRICA LATINA E O CARIBE, 9., 1994, Goiânia. Resumos.... Goiânia: EMBRAPA-CNPAF/CIAT, 1994. Resumo 95.

SAFIR, G.R. Vesicular-arbuscular mycorrizae and crop productivity. In: CARLSON, P.S., ed. The biology of crop productivity. New York: Academic Press, 1980. p.231282.

SANCHEZ, P.A.; SALINAS, J.G. Low-input technologies for managing oxisols and ultisols in tropical América. Advances in Agronomy, San Diego, v.34, p.279-406, 1981.
SANFORD, D.A. Van; MACKOWN, C.T. Variation in nitrogen use efficiency among soft red winter wheat genotypes. Theoretical and Applied Genetics, New York, v.72, p.152163, 1986.

SIDDIQI, M.Y.; GLASS, A.D.M. Utilization index: a modified approach to the estimation and comparison of nutrient utilization efficiency in plants. Journal of Plant Nutrition, New York, v.4, p.289-302, 1981.

SIDDIQI, M.Y.; GLASS, A.D.M.; HSIAO, A.I.; NINJAS, A.N. Genetic differences among wild oat lines in potassium uptake and growth in relation to potassium supply. Plant and Soil, Dordrecht, v.99, p.93-106, 1987.

SINCLAIR, T.R.; HORIE, H. Leaf nitrogen, photosynthesis and crop production use efficiency: a review. Crop Science, Madison, v.29, p.90-98, 1989.

TAYLOR, G.J. The physiology of aluminum tolerance in higher plants. Communication in Soil Science and Plant Analysis, New York, v.19, p.1179-1194, 1988.

WANN, E.V. Sweet corn, that home garden favorite for good nutrition and eating pleasure. Washington: USDA, 1977. (USDA. Information Bulletin, 409).

WARDLE, D.A.; PARKINSON, D. Interactions between microclimatic variables and the soil microbial biomass. Biology and fertility of soils, Berlin, v.1, p.273-280, 1990.

WOODEND, J.J.; GLASS, A.D.M.; PERSON, C.O. Genetic variation under potassium stress. In: GABELMAN, H.W.; LAUGHMAN, B.C., eds. Genetic aspects of plant mineral nutrition. Dordrecht: Martinus Nijhoff, 1987. p.381-391.

WUEST, S.B.; CASSMAN, K.G. Fertilizer-nitrogen use efficiency of irrigated wheat. I. uptake efficiency of preplant versus late-season application. Agronomy Journal, Madison, v.84, p.682-688, 1992.

YOSHIDA, S. Fundamentals of rice crop science. Los Baños: IRRI, 1981. 269p.

YOSHIDA, S. Physiological aspects of grain yield. Annual Review of Plant Physiology, Palo Alto, v.23, p.437-464, 1972.

YOUNGQUIST, J.B.; COX, P.B.; MARANVILLE, J.W. Evaluation of alternative screening criteria for selecting nitrogen-use efficient genotypes in sorghum. Crop Science, Madison, v.32, p.1310-1313, 1992. 